\title{
Determinants of Adopting Electronic Grocery in the Context of Oman
}

\author{
Maha Al Balushi ${ }^{1}$ and Aqeela Al Lawati ${ }^{2}$ \\ ${ }^{1}$ Marketing, Sultan Qaboos University, Al Khod, Oman \\ ${ }^{2}$ Revenue Stamp office, Ministry of Foreign Affairs, Oman
}

\begin{abstract}
Electronic grocery in Oman is a fascinating newly growing market which is facing multiple challenges. Although it creates new job opportunities, it is challenged by the changes of Omani consumers' perceptions and shopping habits. Whereas the adoption of the e-grocery requires less consumer effort and time, it needs to be user-friendly and trustworthy to utilize its full strength. Furthermore, it is challenged by the extent to which adopting a new behavior necessitates considerable time to be fully effective. In this paper, the authors use a sample of 255 responses to study the determinants of adopting electronic grocery in the context of Oman. The determinants represent consumers' perceptions prior to using an e-grocery shopping service, which consists of physical efforts, time pressure, shopping enjoyment, perceived relative advantage, perceived compatibility, and perceived complexity. The model of the study is adapted from the work of Verhoef and Langerake with some modifications to reflect the reality and limitations of this research. The results show a relatively high internal consistency among items of the six variables. The findings of this study show that $62 \%$ of the participants perceive physical effort at in-store shopping and that consumers complaining about time pressure while shopping $(73 \%)$ are motivated to replace their shopping experience with e-grocery. Moreover, this research indicates that shopping enjoyment at physical stores is negatively related to the perceived relative advantage and perceived compatibility factors. In addition, correlation between perceived relative advantages, perceived relative compatibility, and perceived complexity and intention to adopt e-grocery, respectively, is strong.
\end{abstract}

Keywords: Electronic Grocery Shopping; Adoption, Time Pressure, Shopping Enjoyment.

\section{Introduction}

As part of nation's development, Oman has taken very wide steps in the technology world evolvement within no time. After having no facilities and basement structure 40 years ago, today Oman is competing with other countries in providing convenient electronic and digital-based services for citizens and residents. These services have spread in almost all life aspects including essential governmental services (e.g.
Identification card application and renewal, electronic royal Oman police services), health and financial issues (e.g. electronic stock trading, e-banking) and other general services like paying utility bills (ITA, 2010).

Internet made significant changes in human beings' lives. Today, people all around the world are using Internet in their life practices (i.e. trading online, searching, banking, booking airfares). This trend is in line with internet growth and population statistics for

Copyright (C) 2012 Maha Al Balushi and Aqeela Al Lawati. This is an open access article distributed under the Creative Commons Attribution License unported 3.0, which permits unrestricted use, distribution, and reproduction in any medium, provided that original work is properly cited. Contact author: Maha Al Balushi E-mail: mahai175@yahoo.com 
Oman where the percentage of population who use the internet has increased from $3.8 \%$ to $41.7 \%$ from 2000 to 2010 . According to United Nations Agency for Information and Communication Technology Issues (ITU), there are about 1,236,700 Internet users in Oman as of June/2010, which corresponds to $41.7 \%$ of Oman population (Internet World Stats, 2010).

One of the main steps in the global movement towards the digital and electronic-based world, that is also hoped to be adopted in Oman, is providing electronic grocery (e-grocery) services. E-grocery means ordering of the groceries on the internet where the e-grocery stores offer an electronic ordering interface, and the retailer takes care of picking and delivering the goods to the customers (Raijas, 2002). This service does not only give a luxury service for most of the Oman residents but also creates a new market for the several and various domestic shops. It also increases the competition in the sale market, which consequently benefit the customers and the stores or shops.

This paper intends to (1) highlight the perceived advantages and disadvantages pertaining to e-grocery shopping; (2) examine the influence of these perceived advantages and disadvantages on the perceived innovation characteristics of egrocery shopping; and (3) study the effect of the perceived innovation characteristics on customer's behavioral intention to adopt egrocery shopping.

\section{Theoretical Background}

Moving from the traditional way of doing business to electronic business is a hot research topic nowadays. Although various industries in Oman had adopted e-commerce in general, the idea of adopting e-grocery is new. E-grocery offers some advantages and disadvantages to many stakeholders such as customers, suppliers, and country.

\section{Advantages of E-Grocery Shopping}

Online markets must offer advantages over traditional market (Stockdale and Standing, 2004). Providing the e-grocery service will turn into a lot of advantages for the customers and the sellers, collectively. One advantage relates to time and effort saving. For instance, customers not able to go for long hours of shopping due to physical disability, lack of transportation and lack of time, would find e-grocery service very useful because they can purchase the needed items by the tip of their fingers with minimal time and effort required. Ramus and Nielsen (2005) mentioned that time and energy is saved when goods are delivered to the costumer's doorstep and that e-grocery is always open, allowing the customer to shop at any time of the day or night. Another advantage relates to the expansion of the physical space. Retailers are regularly not confined with the physical building of their businesses, but extend to places where internet services are available. This produces more customers, sales, and consequently more profits. It also relieves retailers from pressures on the long cashier lines which in turn lead to less queuing time for customers and less financial errors by cashiers. Moreover, advertising and selling new products is more convenient using the electronic services because apart from being relatively cheaper, it is much faster to cross all boundaries to reach the customers. In addition, it is more cost effective than the traditional market, which relatively costs more. Additional advantage relates to job opportunities. E-grocery opens new market for people to work and develop their country. Although it may seem to result in decrease in labor demand (i.e. cashiers), it creates more job opportunities at different levels. For instance, designers of computer and web site, employees responsible for updating and renewing electronic services, employees responsible for electronic finance and marketing and those who upload and deliver the items to customers destinations. 
Therefore, there would be more net jobs created than jobs lost with the adoption of egrocery service. In summary, providing egrocery service gives a big comfort to customers, increases the customer base for retailers, creates new job for the market, and hence contribute to market development in today's changing environment.

\section{Disadvantages of E-Grocery Shopping}

The disadvantages can be perceived from two different perspectives; consumer and retailer. For the consumer, in general, there is no direct or physical contact with the items chosen via e-grocery expereince. Consequntly, there are a lot of details and infromation that need to be provided for the items by the retailer along with comments or reviews from previous customers. As stated by Raijas (2002), e-grocery shopping demands entirely new shopping habits and attitudes to retail service. Nevertheless, this process helps and guides customers in the decision of choosing their products. Also, egrocery shopping demands experienced internet users (Raijas, 2002). Instead of the ordinary way of negogiating with the seller and asking about the details of the chosen items, the same process takes place digitally. This requires a fair knowledge in browsing the internet to look for the best item for each individual and provide detail and reasonable experience in paying the needed amount electronically as well. Internet users' percentage in Oman have signifiacntly grown. Fifteen years ago, there was no internet serivce in Oman. However today, not only wire internet connection is available, but also wireless (WiFi) is almost everywhere (i.e. coffee shops, universities). As a result, Omanis became familiar with the internet services. Therefore, this disadvantage is perhaps not precieved as a major one in Oman due to the current growth of internet usage. Additionally, e-grocery shopping demands trust. As mentioned above, using the electronic way of buying different things deprive the customer from the direct and physical contact with the selcted items. This requires a trusing relationship between the customer and the seller in terms of the match of what is shown on e-grocery with what the final product looks like. Without that trusting and credible relationship, e-grocery market cannot operate succesfully.

For the retailer, customers may not be willing to buy products via e-grocery means because the quality of the product is uncertain. This is the result of not being able to touch the product physically (Raijas, 2002). In e-grocery, customer is not able to physically touch the product the same way as in the traditional shopping experience. Hence, some of the customers may doubt the quality of the advertized products with actual products. Another disadvantage relates to the quality of the web site and the information provided (Lim, Widdows, and Hooker, 2009). Retailers need to invest in designing a quality website to secure the success of e-grocery shopping for consumers. This means capital and human investment costs in the process that would be incurred by the retailer. Nevertheless, the more the seller's website is clear and enriched with all the needed information (i.e. details about the product, comparison with similar products), the easier and faster it becomes for the customer to choose their products.

\section{The E-Grocery Adoption Process}

Although the internet has been adopted as an important shopping medium with an increasing amount of online sale every year (Kim and Forsythe, 2010), the idea of adopting e-grocery in Oman is relatively new. Therefore, it is considered an innovation in hypermarket industry in Oman. Rogers (1983) identifies five characteristics that influence the rate of adoption of an innovation, which are divided into two categories:

Factors relating to consumers' perceptions prior to use of e-grocery shopping service, which include: 
1. Relative Advantage

2. Compatibility

\section{Complexity}

Factors relating to consumers' perceptions after using e-grocery shopping, which include:

\section{Divisibility}

\section{Communicability}

These characteristics can be considered in relation to e-grocery shopping experience. According to Verhoef and Langerake (2001), the perceived relative advantage refers to the degree to which consumers perceive egrocery shopping superior to in-store shopping. The perceived compatibility refers to the degree to which consumers perceive egrocery shopping match their shopping needs. The perceived complexity refers to the degree to which consumers find e-grocery shopping difficult to understand. The perceived divisibility refers to the degree to which e-grocery shopping can be tried on a limited basis. The perceived communicability refers to the degree to which the benefits of use of e-grocery shopping are observable or describable to others. Since e-grocery shopping is not yet formalized or activated in Oman at the time of this research, this study focuses on the three characteristics that consumers were able to evaluate prior to using an e-grocery shopping service. Furthermore, this study is limited to investigating consumers' behavioral intentions to adopt e-grocery shopping instead of the actual adoption.

\section{Model and Hypotheses}

In this research, the model that explains Omani consumers' behavioral intention to adopt e-grocery shopping is shown in Figure 1. This model was adapted from the work of Verhoef and Langerake (2001) with some modifications to reflect the reality and limitations of this research. In particular, unlike the original model purposed by Verhoef and Langerake, the structural relationship between the three factors_ perceived relative advantage, compatibility, and complexity_ is not examined because of different statistical tools employed in this research.

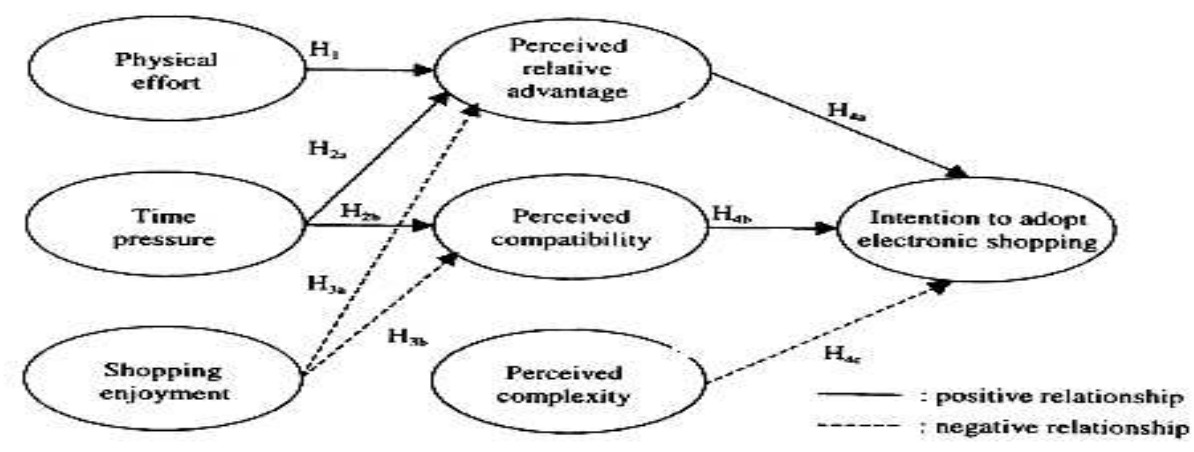

Fig. 1. Consumers' intention to adopt electronic grocery shopping.

Source. Verhoef and Langerak, $2001(p .277)$

\section{Physical Effort}

From the customer point of view, the physical effort in any shopping includes transportation from customer residence to the hypermarket for shopping purposes and vice versa for carrying their shopping items. On the one hand, it means using public transportation, which would be cheaper and easier travelling to the destination (house, or 
shop) but not convenient after being loaded with goods bought. On the other hand, using private transportation, as widely witnessed in Oman, is more expensive but faster to get to the destination. It also means finding a good parking space. Nevertheless, in both situations, the consumers incur transportation expenses as well as shopping time loss.

Thus, the authors hypothesize that:

$\mathbf{H}_{1}$ : The more physical effort required in physical grocery (in-store), the more the customers are encouraged to replace it with e-grocery.

\section{Time Pressure}

With increasing number of people who work in the private sector in Oman, many spend more time at their offices due to their work nature. At the same time, they have to take care of their grocery needs, which put extra pressure on their schedule. In addition, more time is needed to travel to and from the hypermarket. Furthermore, the increasing crowd in the hypermarkets requires crossing from one end to another to collect the needed items, which in turn results in more time needed to finish grocery shopping.

Thus, the authors hypothesize that:

$\mathbf{H}_{2 \mathrm{a}}$ : The more time lost in physical grocery, the larger the perceived relative advantage of e-grocery shopping will be.

$\mathbf{H}_{2 \mathbf{b}}$ : The more time lost in physical grocery, the larger the perceived compatibility of egrocery shopping will be.

\section{Shopping Enjoyment}

Despite some logistic problems (i.e. items are not displayed in their common places where the consumer is accustomed to, hassle of picking bulky shopping items with infants) perceived by some of the customers, others perceive shopping with family as a source of enjoyment. Particularly, they find shopping with family and spending a full day with them in one of the hypermarkets as a source of entertainment. Generally, Omani families keep strong ties with family members. Therefore, they enjoy going shopping alltogether. Making a physical contact with the items sold, witnessing new offers, and enjoying free product samples are some factors that make physical presence in the hypermarkets a source of enjoyment for considerable number of customers. Oman is no exception. This means that these consumers would perhaps not perceive high value in e-grocery shopping.

Thus, the authors hypothesize that:

$\mathbf{H}_{3 \mathbf{a}}$ : The larger the enjoyment of in-store grocery felt by Omanis, the smaller the perceived relative advantage of e-grocery shopping will be.

$\mathbf{H}_{3 \mathbf{b}}$ : The larger the enjoyment of in-store grocery felt by Omanis, the smaller the perceived compatibility of e-grocery shopping will be.

Intention to Adopt Electronic Grocery Shopping

Although being time consuming and physically exhausting to do the groceries, it needs to be guaranteed and trusted. Oman's Information Technology Authority's (ITA) web site, where the entire e-payment transactions take place, gives Omanis confidence to pay online. Moreover, as it is a government web site, people trust it as a credible source. In addition, it has a simple interface and user friendly web page. Consequently, for any electronic groceries to be successful it has to be easy, user-friendly, and trusted. With the increase in the young population adoption of electronic life style, a promising number of customers would be available for these facilities. However, as older generations are not familiar with the elife style and adopting a new behavior is more challenging to be induced in this age group, a proportion of customers will continue using the traditional groceries no 
matter how easy, attractive, and convenient is the e-grocery build up. In this study, the authors hypothesize that:

$\mathbf{H}_{4 a}$ : There is a positive relationship between the perceived relative advantage and the (behavioral) intention to adopt e-grocery shopping by Omanis.

$\mathbf{H}_{\mathbf{4 b}}$ : There is a positive relationship between the perceived compatibility and the (behavioral) intention to adopt e-grocery shopping by Omanis.

$\mathbf{H}_{4 \mathbf{c}}$ : There is a negative relationship between the perceived complexity and the (behavioral) intention to adopt e-grocery shopping by Omanis.

\section{Significant Difference Effects}

The study on hand does not only examine the characteristics that influence the rate of adoption of an innovation, but also explores the possible significant difference effects of the consumer characteristics of gender, age, marital status, and education on the hypothesized relationships.

\section{Method}

\section{Sample Size and Data Collection}

The sample size consisted of 400 randomly selected Omani citizens from three different organizations in Muscat region of Oman, where no electronic grocery shopping is available at the time of the study. The three organizations were randomly selected from the list of organization in Oman telephone directory's Green Pages for the year 2010. The survey was back translated from English to Arabic, by two bilingual associates whose native language is Arabic, to secure feedback from Arabic speaking respondents and check the consistency of translation. Therefore, the original English version was used along with Arabic. The questionnaire along with a cover letter explaining the purpose of the study and assuring the confidentiality of responses for respondents in both languages, Arabic and English, was distributed.

\section{Measures}

All responses were recorded on a five-point scale (strongly disagree, disagree, neutral, agree, and strongly agree), with the exception of the intention of consumers to adopt electronic grocery shopping. The items are provided in appendix (A). The physical effort of in-store shopping refers to the extent to which the transportation for the purchase of grocery products is hard and exhausting for the consumer. It is measured by two items adopted from the work of Eastlick (1993). Time pressure refers to the extent to which the consumer is under pressure of time that ultimately affects the experience of grocery shopping. It is measured by three items adopted from Srinivasan and Ratchford's (1991) study. Shopping enjoyment refers to the enjoyment of in-store grocery felt by consumer. It is measured by four items adopted from the work of Dawson, Bloch, and Ridgeway (1990). The perceived relative advantage of e- grocery shopping refers to the extent to which consumers perceive e-grocery shopping superior to in-store shopping. It is measured by three items adopted from Frambach, Barkema, Nooteboom, and Wedel (1998). The perceived compatibility egrocery shopping refers to the extent to which consumers perceive e-grocery shopping match their shopping needs. It is measured by three items adopted from Frambach, Barkema, Nooteboom, and Wedel (1998). The perceived complexity of egrocery shopping refers to the extent to which consumers find e-grocery shopping difficult to understand. It is measured by four items adopted from Frambach, Barkema, Nooteboom, and Wedel (1998). The behavioral intention refers to consumers' willingness to adopt e-grocery shopping. It is measured by a single item adopted from Juster (1966). The responses for this item were recorded on 11-point scale anchored by 0 (absolutely not) and 10 (absolutely yes). 


\section{Results}

Out of 400 surveys distributed, 255 surveys returned. This represents $64 \%$ response rate. Factor analysis was used to test the model across 18 items. Kaiser-Meyer-Olkin (KMO) of 0.650 is considered good value for the data set. It indicates that the patterns of correlations are relatively compact and the factors are reliable. Barttetts test of sphericity yields p-value of 0.00 , which is less than 0.10 level of significance, therefore the variables are significant and the factor analysis is appropriate. The analysis supports that the 18 items which were used in the survey to test the model can be displayed as six factors. Moreover, reliability analysis was examined and yielded Cronbach's Alpha that ranged between 70\% and 93\%, as indicated in Table 1. Reliability is the proportion of variance attributable to the true score of the latent variable (DeVellis, 2003). The results show a relatively high internal consistency among items of the six variables. Therefore, all the items have to be included to measure consumer adoption of egrocery.

Table 1: Reliability Estimates

\begin{tabular}{|l|c|c|}
\hline Factors & \# of Items & Cronbach Alpha \\
\hline Physical efforts & 2 & 0.70 \\
\hline Time pressure & 3 & 0.93 \\
\hline Shopping enjoyment & 4 & 0.82 \\
\hline Perceived relative advantage & 3 & 0.88 \\
\hline Perceived compatibility & 3 & 0.76 \\
\hline Perceived complexity & 4 & 0.90 \\
\hline
\end{tabular}

\section{Testing the Hypotheses}

The hypothesized relationships were examined using correlation analysis of SPSS 19.0 for windows.

Physical Effort: To test the impact of the physical effort on the relative perceived advantage of e-grocery, their items (in appendix A) are correlated. The percentage of people who agreed that the physical grocery required more physical effort is $62 \%$. The correlation between the physical effort and the relative perceived advantage of egrocery service is strong because it yields a correlation coefficient equal to +0.80 . This supports $\mathrm{H}_{1}$. In particular, $64 \%$ of variance in physical effort can be explained by the variance in the relative perceived advantage of e-grocery.

Time Pressure: To test the impact of the time pressure on the relative perceived advantage of e-grocery, their items (in appendix A) are correlated. The correlation between the time lost in physical grocery stores and the perceived relative advantage of e-grocery is strong because it yields a correlation coefficient equal to +0.86 . In particular, $74 \%$ of variance in time pressure can be explained by the variance in the perceived relative advantage of e-grocery. In addition, $73.1 \%$ agreed that physical shopping required more time than an egrocery shopping. Thus, this supports $\mathrm{H}_{2 \mathrm{a}}$. The correlation between the time lost in physical grocery stores and perceived compatibility of e-grocery is strong too because it yields a correlation coefficient equal to +0.79 . Thus, this supports $\mathrm{H}_{2 \mathrm{~b}}$.

Shopping Enjoyment: To test the impact of the shopping enjoyment on the relative advantage of e-grocery, their items (in appendix A) are correlated. The correlation between the shopping enjoyment in physical grocery stores and the perceived relative advantage of e-grocery is negatively strong because it yields a correlation coefficient equal to- 0.78 . In particular, $61 \%$ of variance in shopping enjoyment can be explained by 
the variance in the relative advantage of egrocery. Thus, this supports $\mathrm{H}_{3 \mathrm{a}}$.

The correlation between the shopping enjoyment in physical grocery stores and the perceived relative compatibility of e-grocery is negatively strong because it yields a correlation coefficient equal to -0.82 . In particular, $67 \%$ of variance in shopping enjoyment can be explained by the variance in the perceived relative compatibility of egrocery. Thus, this supports $\mathrm{H}_{3 \mathrm{~b}}$.

Perceived Relative Advantage: To test the impact of perceived relative advantage on intention to adopt e-grocery, their items (in appendix A) are correlated. The correlation between perceived relative advantages and intention to adopt e-grocery is strong because it yields a correlation coefficient equal to +0.83 . In particular, $69 \%$ of variance in perceived relative advantage can be explained by the variance in willingness to adopt e-grocery. Thus, this supports $\mathrm{H}_{4 a}$.

Perceived Compatibility: To test the impact of perceived relative compatibility on intention to adopt e-grocery, their items (in appendix A) are correlated. The correlation between perceived relative compatibility and intention to adopt e-grocery is strong because it yields a correlation coefficient equal to +0.70 . In particular, $49 \%$ of variance in perceived relative compatibility can be explained by the variance in willingness to adopt e-grocery. Thus, this supports $\mathrm{H}_{4 \mathrm{~b}}$.

Perceived Complexity: To test the impact of perceived complexity on intention to adopt egrocery, their items (in appendix A) are correlated. The correlation between perceived complexity and intention to adopt e-grocery is negatively strong because it yields a correlation coefficient equal to -0.68. In particular, $46 \%$ of variance in perceived relative complexity can be explained by the variance in willingness to adopt e-grocery. Thus, this supports $\mathrm{H}_{4 \mathrm{c}}$.

\section{Testing for Significant Difference Effects}

In order to test for possible significant difference effects on the rate of adoption of egrocery, t-test and ANOVA analysis were used.

Gender: In this study, $47.8 \%$ of responses were from male and $52.2 \%$ of responses were from female. T-test was run to examine the difference between male and female in the rate of adoption of e-grocery. The analysis shows a t-value of 1.75 and the probability of error of 0.50 , which is greater than the significance level of 0.05 . Therefore, there is no significant difference between male and female in the rate of adoption of egrocery.

Age: In this study, $61 \%$ of responses were from the age group of 15-24 years old, $27 \%$ of responses were from the age group of 2534 years old, about $7 \%$ of responses were from the age group of 35-44 years old and only $5 \%$ of responses were from the age group of 45-54 years old. None of the responses were from age group less than 14 years old, which is obviously not the target of e-grocery service. Also, the age group of 55 years old and above had no responses. This is perhaps because e-grocery is not appealing to this target in Oman. In particular, in the age group of 15-24 years old, $90 \%$ is supporting e-grocery, whereas $4 \%$ is not supporting and $6 \%$ are not neutral in their view. ANOVA was run to test whether there is any difference among age groups in the rate of adopting e-grocery. The p-value of 0.01 is less than alpha 0.05 . Therefore, there is a significant difference between age groups in the rate of adoption of e-grocery. 
Marital Status: In this study, $50 \%$ of responses were from single group, $30 \%$ of responses were from married group, $20 \%$ of responses were from divorced group and none of responses were from widows group. In particular, the married group is highly willing to adopt e-grocery as reflected by $98 \%$ of support responses. ANOVA was run to test whether there is any difference among the various marital status groups in the rate of adopting of e-grocery. A p-value of 0.03 is less than alpha 0.05 . Therefore, there is a significant difference between marital status groups in the rate of adoption of e-grocery.

Education Level: In this study, 25\% of responses were from pre-college group, 70\% of responses were from college group and only $5 \%$ of responses were from post-college group. College education group has a higher percentage and this is perhaps because egrocery is appealing to this target group in Oman. In particular, $80 \%$ of them have selected 8 on a scale of 11 for questions that represent the intention to adopt e-grocery in the future. ANOVA was run to test whether there is any difference between various education levels in the rate of adopting egrocery. A p-value of 0.04 is less than alpha 0.05. Therefore, there is a significant difference between educational level groups in the rate of adoption of e-grocery.

\section{Discussion}

This study was conducted to test the relationships between variables that have impact on the Omani consumer adoption of e-grocery. Below is a brief summary that discusses the main effect variables and the significant difference effect variables.

\section{Main Effects}

The findings of this study show that consumers who perceive a high percentage of physical effort at in-store shopping and those who complain about time pressure while shopping will be encouraged to replace their shopping experience with e-grocery. It can be clearly seen from the analysis that
$64 \%$ of variance in physical effort was explained by variance in the perceived relative advantage of e-grocery service. Moreover, $74 \%$ of variance in time pressure was explained by variance in perceived relative advantages of e-grocery. The results are in tandem with Raijas (2002) who pinpoints that the benefits of the electronic grocery shopping is time and effort saving.

This study also shows that consumers who are willing to change their behavior and attitudes are looking forward to adopt egrocery. Oman has an increasing percentage of internet usage in the past 10 years; thus, people have changed their behaviors and attitudes towards adopting the digital life. As mentioned earlier, it is highly important that the way shopping is conducted fits the consumer's life style and everyday life (Raijas, 2002). Moreover, this research indicates that shopping enjoyment at physical stores is negatively related to the perceived relative advantage and perceived compatibility factors of e-grocery. This fact supports that e-grocery is more enjoyable and compatible with consumer's current changing lifestyle and needs than in-store shopping. According to Keh and Shieh (2010), customers enjoy using technology in their daily life. Hence, ordering grocery online is considered an entertainment for them.

Nevertheless, shopping for groceries, whether online or off-line, is important in today's consumer life style. Once shoppers become comfortable with their means of shopping, they are likely to stick to the preferred service. Generating repeat business is a key success for any e-commerce (Keh and Shieh, 2010)

\section{Significant Difference Effects}

On the one hand, the findings of this study reveal that the age group between 15 and 24 years old, of which college student category mostly falls, supports the idea of e-grocery. On the other hand, previous studies found that the age group between 36 and 45 years 
old are willing to purchase grocery online (Raijas, 2002). The difference in the results perhaps relates to the fact that Oman is a new country in the digital world and that those who represent age group between 36 to 45 years old in Oman are least likely to be willing to change their behavior to adopt the new technology or it may take a while for the change to take place within this age group. In addition, nowadays women work out-side their houses and have lots of duties and responsibilities excluding those of in-house. Therefore, they appreciate the idea of egrocery, especially those who are married, where they could save time and physical effort in getting the needed items. This supports what Raijas (2002) maintained that the purpose of choosing an e-grocery store is avoidance of grocery picking and transport as well as time saving.

\section{Managerial Implications}

The main goal of the study is to determine the various challenges of e-grocery experience in Oman that affect its success in persuading people into adopting it. The results do support the relationships posited in the model of this study. They also support conclusions and views of earlier studies particularly that physical effort and time pressure are significantly related to the adoption of e-grocery. It is hence recommended that suppliers and retailers of grocery products in Oman build a good electronic channel to provide such service. Also, retailers who are willing to provide egrocery service have to be aware of providing the service in a simple and convenient way through providing a userfriendly website with the required information and an easy way to allocate the product. This would allow speeding up the process of adopting e-grocery in Oman. Moreover, the results show that customers who represent the age group of 45-54 years old and above in Oman are not willing to change their behavior to adopt the digital word. Therefore, potential providers of the egrocery service should treat this segment differently.

\section{Limitations and Suggestions for Future}

This study is limited by the sample elements that were drawn from the Muscat region of Oman only. Also, it was beyond the scope of this study to examine the factors relating to consumers' perceptions after using e-grocery shopping; divisibility and communicability, since e-grocery service is not yet available in Oman at the time of this research. Therefore, future studies can consider these factors once the e-grocery service is activated in Oman.

In summary, this study has tested few factors which may be replicated in future using different geographic area, and perhaps other moderating factors such as income, number of family members and knowledge level of information technology. As an innovative service in Oman, e-grocery requires good marketing methods and challenging customers who take the risk to try a new service.

\section{Appendix (A)}

\section{Physical Effort}

I think the transportation of my bought grocery products is hard

The transportation of my bought groceries is exhausting

\section{Time Pressure}

I usually find myself pressed for time

I am often in a hurry

Usually there is so much to do that I wish I had more time

\section{Shopping Enjoyment}

I like to shop in shops that I do not know

I really like to visit different supermarkets 
I like to meet other people in the supermarket

I consider shopping a big hassle (reversed)

\section{Perceived Relative Advantage}

Electronic shopping is less exciting

Using electronic shopping saves much time

Using electronic shopping makes me less dependent of opening hours

\section{Perceived Compatibility}

Electronic shopping suits my person

Electronic shopping requires few adaptations in my personal life

Electronic shopping yields little problems for me

\section{Perceived Complexity}

With electronic shopping it is hard to find the needed products

With electronic shopping it is difficult to order products

With electronic shopping it is problematic to compare products

Electronic shopping is complex

\section{Intention to Adopt Electronic Grocery Shopping}

To which extent you intent to use electronic shopping to obtain your groceries in the near future

\section{References}

Dawson, S., Bloch, P. H. \& Ridgeway, N. M. (1990). 'Shopping Motives, Emotional States, and Retail Outcomes,' Journal of Retailing, 66, 408-427.
Devellis, R. F. (2003). Scale Development: Theory and Applications, California, USA, Sage Publications.

Eastlick, M. A. (1993). "Predictors of Videotex Aoption," Journal of Direct Marketing, 7, 6674.

Frambach, R. T., Barkema, H. G., Nooteboom, B. \& Wedel, M. (1998). "Adoption of a Service Innovation in the Businss Market: An Empirical Test of Supply-Side Variables," Journal of Business Research, 41, 161-174.

Information Technology Athurity of Oman (2010). Avalible at http://www.ita.gov.om/ITAPortal/Governm ent/Government.aspx. Access; October 20, 2010.

Internet World Stats Usage and Population Statistics (2010). avalible at http://www.internetworldstats.com/me/om .htm.

Juster, F. T. (1966). "Consumer Buying Intention and Purchase Probability: An Experiment in Survey Design," Journal of the American Statistical Association, 61, 658-696.

Keh, H. T. \& Shieh, E. (2001). "Online Grocery Retailing: Success Factors and Potential Pitfalls," Journal of Eetailing and Consumer Service, 17, 278-285.

Kim, J. \& Forsythe, S. (2010). "Factors Affecting Adoption of Product Virtualization Technology for Online Consumer Electronics Shopping," International Journal of Retail and Management, 38(3), 190-204.

Lim, H., Widdows, R. \& Hooker, N. H. (2009). "Web Content Analysis of E-Grocery Retailers: A Longitudinal Study," International Journal of Retail and Distribution Management, 37(10), 839-851.

Raijas, A. (2002). "The Consumer Benefits and Problems in the Electronic Grocery Store," Journal of Retailing and Consumer Services, 2 (9), 107 - 113. 
Ramus, K. \& Nielsen, N. A. (2005). "Online Grocery Retailing: What Do Consumers Think?," Internet Research, 15 (3), 335-352.

Rogers, E. M. (1983). Diffusion of Innovation. Free Press, New York.

Srinivasan, N. \& Ratchford, B. T. (1991). "An Empirical Test of an External Search for Automobiles," Journal of Consumer Research, $18,233-242$.

Stockdale, R. \& Standing, C. (2004). "Benefits and Barriers of Electronic Marketplace Participation: An SME Perspective," Journal of Enterpriseninformation Management, 17(4), 301-311.

Verhoef, P. C. \& Langerak, F. (2001). "Possible Determinants of Consumers' Adoption of Electronic Grocery Shopping in the Netherlands," Journal of Retailing and Consumer Services, 8, 275-285. 